\title{
Bioactive properties of Japanese fermented fish paste, fish miso, using koji inoculated with Aspergillusoryzae
}

\author{
Anupam Giri, Midori Nasu, Toshiaki Ohshima \\ Department of Food Science and Technology, Tokyo University of Marine Science and Technology, Tokyo, Japan \\ Email address: \\ ag2002dr@yahoo.co.in (A. Giri), nasugakko999@hotmail.com (M. Nasu), tohshima@kaiyodai.ac.jp (T. Ohshima)
}

\section{To cite this article:}

Anupam Giri, Midori Nasu, Toshiaki Ohshima. Bioactive Properties of Japanese Fermented Fish Paste, Fish Miso, Using Koji Inoculated With Aspergillusoryzae. International Journal of Nutrition and Food Sciences. Vol. 1, No. 1, 2012, pp. 13-22.

doi: 10.11648/j.ijnfs.20120101.12

\begin{abstract}
This research was evaluated the antioxidant activity of fish miso, a newly developed fermented fish paste prepared from horse mackerel meat and the fermentation of traditional Japanese koji inoculated with Aspergillusoryzae. The antioxidant activities in different in vitro models, including DPPH, hydroxyl, nitric oxide and carbon-centered radical-scavenging activity (RSA), and reducing power ability (RPA), were investigated during the fermentation period along with 2 different storage conditions. The antioxidant activity of matured fish miso was also evaluated using a linoleic acid oxidation model system by monitoring hydrogen peroxide formation and oxygen absorption. The RSA against all the types of radicals measured by electron spin resonance showed an increase over prolonged fermentation periods and during storage at high temperatures. However, the RPA showed a rapid increase during the early stages of fermentation. The SDS-PAGE profile of fish miso peptides during the early stages of fermentation indicated the occurrence of hydrolysis, suggesting the involvement of low-molecular-weight peptides in the RSA and reducing power of fish miso. Partial purification of these peptides by using an online-HPLC-DPPH flow injection analysis system and further characterization by thin layer chromatography and molecular weight distribution clearly indicated that low-molecular-weight peptides $(<500 \mathrm{Da})$ were potent antioxidants. These data suggest that the antioxidant activity of fish miso could be substantially improved by fermenting Aspergillus (koji) mold. This approach provides a novel strategy to enhance the value of trash fish, such as horse mackerel.
\end{abstract}

Keywords: Fish Miso, Horse Mackerel Meat, Aspergillusoryzae, Radical Scavenging, Peptide

\section{Introduction}

The free radicals generated by endogenous metabolic processes in food systems or exogenous chemicals may cause oxidative damage by oxidizing biomolecules, which can result in tissue damage and cell death [1]. Recently, there has been a significant interest in natural antioxidants, such as antioxidative peptides, because they can protect the human body from free radicals and slow the progression of many chronic diseases in addition to providing nutritional value [2,3]. Several traditional fermented soybean foods, including miso, natto, tempeh, sufu, and douchi, possess many advantageous properties such as free radical-scavenging activity and reducing power and ion-chelating abilities [4,5,6]. Miso has been used as a traditional daily seasoning for several centuries in Japan. It is also used to reduce hypertension [7], colonic aberrant crypt foci [8], cerebrovascular disease [9], and plasma cholesterol levels [10]. In Indonesia, the fungus used for the preparation of miso belongs to a genus other than Aspergillus [11]. The acceptable taste [12,13], antioxidant effects [14,15], and cholesterol-reducing functions [16,17] of this preparation of miso have been previously reported.

Aspergillus spp. have been used as starter organisms for the preparation of koji for thousands of years. They are typically used in the fermentation industry to produce vitamins [18], enzymes [19], organic acids [20], antibiotics [21], soy sauce, miso, and sake [22]. The koji contributes to the color, flavor, and aroma, which are important for the overall attributes of the resulting fermented foods [19]. Raimbault and Alazard [23] performed a solid-state fermentation of Aspergillusoryzaeon tapioca and observed that the amount of inoculated conidia was related to fermentation efficiency. In the traditional Japanese food industry, A. oryzae, A. sojae, and A. awamoriare frequently 
used to prepare koji. In addition, rice, wheat, and soybean are used to produce various seasonings, alcohols, and foods such as sake (distilled rice alcohol), soy sauces, miso, and the seasoning minin [19]. Considering the novel uses of Aspergillus, several researchers have tried to ferment meat-based products using Aspergillus. Yin and others [24,25] reported that $A$. oryzaecan be used to produce multi-enzyme complexes that hydrolyze minced mackerel. The acceptability, nutritional value, and functionality of the resulting the hydrolysate, such as antioxidant activity, proliferation of both human hybridoma and mouse macrophage cells after $1 \mathrm{~h}$ of hydrolysis by A. oryzae, and LAB fermentation have been reported to be improved. We attempted to develop a miso-like product, such as fish miso, by utilizing several trash fish with Aspergillus inoculated koji. There are very few studies on the nutritional and taste aspects of fish miso, and its antioxidative properties have not been reported.

In an attempt to utilize and develop trash fish into functional foods, we report the effects of fermentation using A. oryzae (koji) mold on the hydrolysis of fish protein, which could potentially result in an increase in its antioxidant activity. We evaluated the antioxidant activity of fish miso over the course of its fermentation and used a couple of different storage conditions. We also partially purified and characterized the potent radical-scavenging compounds in fish miso.

\section{Materials and Methods}

\subsection{Materials}

Horse mackerel (Trachurusjaponicus) with body weights of $67 \pm 3 \mathrm{~g}$ and fork lengths of $16.9 \pm 0.4 \mathrm{~cm}$ were caught by purse seiners offshore near Nagasaki Prefecture. The fish were stored for a month at $-50^{\circ} \mathrm{C}$ until use. A pure strain of $A$. oryzae (koji) mold (M1 mold) was purchased from Nihon Jozo Kogyo, Tokyo, Japan.

\subsection{Chemicals}

All authentic standards of volatile compounds used for identification and other analyses were of GC-analytical grade and purchased from Tokyo Chemical Industry, Tokyo, Japan.

\subsection{Preparation of Fermented Fish Meat Paste: Fish Miso}

Koshihikari rice (Oryza sativa) produced in Nigata prefecture, Japan, was soaked in 2 volumes of fresh water for $12 \mathrm{~h}$ at room temperature and subsequently steamed at $90^{\circ} \mathrm{C}$ for $1 \mathrm{~h}$. After cooling to room temperature, the rice was inoculated with the koji mold, incubated at $35^{\circ} \mathrm{C}$ for $48 \mathrm{~h}$, and the resulting malt-rice was used as koji, the starter for fermentation. Fresh fisheswere beheaded, gutted, washed, skinned, and deboned using a model NF2 deboning machine (Bibun Kikai Seisakusyo Co. Ltd., Fukuyama, Japan) equipped with a drum containing perforations $(4 \mathrm{~mm}$ in diameter). The fish meat was ground separately with a model M-22 grinder (Nantsune Tekko, Osaka, Japan) and then placed into an aluminum-coated, heat-stable polyvinylchloride pouch, which was subsequently vacuum-sealed and steam-heated at $90^{\circ} \mathrm{C}$ for $1 \mathrm{~h}$. Portions were then filter pressed at $2 \mathrm{MPa}$ to achieve moisture contents between $50 \%$ and $55 \%$ by using a model KS-1 filter press (Komagata Kikai Seisakusho, Tokyo, Japan). The resulting dehydrated meat was washed 3 times with 5 volumes of fresh water before pressing. Fish meat, kojiand salt were mixed in a grinder at a ratio of 5:5:1 (wet weight). Approximately $3 \mathrm{~kg}$ of fish paste was packed into a $5-\mathrm{L}$ plastic container and fermented at a temperature between $25^{\circ} \mathrm{C}$ and $30^{\circ} \mathrm{C}$ for 90 days. The contents of each container were mixed thoroughly once a month. The prepared material was named fish miso, which means "fermented fish paste" in Japanese. After 90 days of fermentation, fish miso products were stored at 2 different temperatures $-10^{\circ} \mathrm{C}$ and $25^{\circ} \mathrm{C}$. The products were sampled at $0,15,30,60,90,135,180$, 270 , and 365 days for analysis.

\subsection{Water Extraction of Fish Miso for Experimental Studies}

Aliquots of miso (2 g) were thoroughly mixed in phosphate buffered saline $(10 \mathrm{mM}, \mathrm{pH} 7.4 ; 20 \mathrm{~mL})$ and centrifuged at $1300 \mathrm{rpm}$ for $10 \mathrm{~min}$. The supernatant (dry matter content $36.3 \pm 5.6 \mathrm{mg} / \mathrm{mL}$ ), lyophilized extract, or a mixture of both was used for antioxidant assays.

\subsection{Radical Scavenging Assay}

\subsubsection{DPPH Radical Scavenging Assay}

The DPPH radicalsscavenging activity was measured using a modified method described by Nanjo et al. [26]. In brief, fish miso extract $(50 \mu \mathrm{L})$ was added to a DPPH solution $(100 \mu \mathrm{M}$ in $85 \%$ ethanol; $50 \mu \mathrm{L})$ and vortexed. After $15 \mathrm{~min}$, the mixture was transferred into a sealed $50-\mu \mathrm{L}$ capillary tube to measure the DPPH radical spin resonance. The following parameters were used along with the JES-TE300 electron spin resonance (ESR) spectrometer (JEOL, Tokyo, Japan): microwave power, $1.2 \mathrm{~mW}$; microwave frequency, 9149.3 MHz; magnetic field, $325.5 \pm$ $25 \mathrm{mT}$; and sweep time, $30 \mathrm{~s}$.

\subsubsection{Hydroxyl Radical Scavenging Assay}

Hydroxyl radicals were generated by the Fenton reaction [27]. Either fish miso extract $(50 \mu \mathrm{L})$ or an equal volume of phosphate buffer (10 mM, pH 7.4, control) was added to 0.3 M DMPO $(50 \mu \mathrm{L})$ and $10 \mathrm{mM} \mathrm{FeSO}_{4}(50 \mu \mathrm{L})$. The reaction was initiated by the addition of $10 \mathrm{mM} \mathrm{H}_{2} \mathrm{O}_{2}(50 \mu \mathrm{L})$ and then transferred to a sealed $50-\mu \mathrm{L}$ capillary tube. The DMPO-OH adduct was observed after $2.5 \mathrm{~min}$ using a JES-TE300 ESR spectrometer (JEOL) using the parameters listed above.

\subsubsection{Nitric Oxide Radical Scavenging Assay}

A nitric oxide (NO) radical was prepared by dissolving potassium nitrosodisulfonate, $\mathrm{K}_{2} \mathrm{NO}\left(\mathrm{SO}_{3}\right)_{2}$, or Fremy's salt 
in a saturated solution of $\mathrm{Na}_{2} \mathrm{CO}_{3}$. The resulting $50 \mu \mathrm{M}$ solution $(50 \mu \mathrm{L})$ was mixed with miso extract $(50 \mu \mathrm{L})$. After $5 \mathrm{~min}$, the mixture was transferred to a sealed capillary tube, and the resulting spin adduct was monitored.

\subsubsection{Carbon-Centered Radical Scavenging Assay}

Carbon-centered radicals were generated by AAPH [28]. Miso extract $(50 \mu \mathrm{L})$ was mixed with 4-POBN (40 mM; 50 $\mu \mathrm{L})$ and $\mathrm{AAPH}(40 \mathrm{mM} ; 50 \mu \mathrm{L})$ and incubated at $37^{\circ} \mathrm{C}$ for $30 \mathrm{~min}$. The resulting mixture was then transferred to a sealed $50-\mu \mathrm{L}$ capillary tube, and the spin adduct was monitored.

The ESR signals obtained for different radicals were quantified by calculating the area under curve using Mathematica 6.0 software (Wolfram Research, Inc. Champaign, USA).

\subsection{Reducing Power Assay}

The reducing power of the miso extract was determined according to the method described by Oyaizu [29]. Fish miso extract $(2.5 \mathrm{~mL})$ was mixed with $200 \mathrm{mmol} / \mathrm{L}$ sodium phosphate buffer ( $\mathrm{pH} 6.6 ; 2.5 \mathrm{~mL}$ ) and $1 \%$ potassium ferricyanide $(2.5 \mathrm{~mL})$. The mixture was incubated at $50^{\circ} \mathrm{C}$ for $20 \mathrm{~min}$. Subsequently, $10 \%(\mathrm{w} / \mathrm{v})$ trichloroacetic acid $(2.5 \mathrm{~mL})$ was added, and the mixture was centrifuged at 650 $\mathrm{rpm}$ for $10 \mathrm{~min}$. The upper layer $(5 \mathrm{~mL})$ was mixed with deionized water $(5 \mathrm{~mL})$ and $0.1 \%$ of ferric chloride $(1 \mathrm{~mL})$, and the absorbance was measured at $700 \mathrm{~nm}$. Ascorbic acid, TBHQ, and BHA were used as standards.

\subsection{Qualitative Analysis of Peptides by SDS-PAGE}

The peptide profile of fish miso prepared from horse mackerel meat was analyzed by sodium dodecyl sulfate-polyacrylamide gel electrophoresis (SDS-PAGE) by using a $15 \%$ resolving gel in $1.5 \mathrm{M}$ Tris- $\mathrm{HCl}, \mathrm{pH} 8.8$, and a $3 \%$ stacking gel in $0.5 \mathrm{M}$ Tris-HCl, pH 6.8 (Sigma, St. Louis, MO, USA). The protein fractions were loaded into the wells of the gel and electrophoresed using $1 \times$ running buffer $(25$ mMTris/192 mM glycine, $\mathrm{pH} 8.3,0.5 \%$ SDS). A standard molecular weight marker (TEFCO Protein MW Marker II; TEFCO, Japan) was loaded onto the gel to compare the molecular weights of the proteins in different samples. After electrophoresis, the gels were stained with CoomassieBrilliant Blue (CBB R-250).

\subsection{Assessment of Antioxidative Activity by the Inhibition of Lipid Peroxidation}

Following a modified method of Osawa\&Namiki [30], linoleic acid was oxidized using a linoleic acid model system to measure the antioxidative activity of matured miso extracts. Briefly, miso extract ( $1 \mathrm{~mL}$ ) was added to a mixture of $99.5 \%$ ethanol $(5 \mathrm{~mL})$, purified linoleic acid $(0.065 \mathrm{~mL})$, and distilled water $(4 \mathrm{~mL})$, and it was vigorously mixed. For positive and negative control assays, the fish miso extract was substituted with $500 \mathrm{ppm}$ of either of the standard antioxidants, BHA or Trolox ${ }^{\circledR}(1 \mathrm{~mL})$, and PBS (10 mM, pH
7.4; $1 \mathrm{~mL}$ ). Using a 22-mL glass vial tightly sealed with an aluminum cap lined with polytetrafluoroethylene/silicone, the mixed solution (Supelco, Bellefonte, PA) was incubated at $40^{\circ} \mathrm{C}$ in the dark. The degree of linoleic acid oxidation was measured at $48-\mathrm{h}$ intervals by monitoring the total hydrogen peroxide content as well as oxygen absorption.

The total amount of hydroperoxide was measured using DPPP as a fluorescent reagent and a flow-injection analysis system equipped with a fluorescence detection system [31]. The oxygen uptake was measured by gas chromatography using the method described by Ohshima et al. [32].

\subsection{Screening of Radical-Scavenging Fractions using an Online HPLC-DPPH Method}

An online HPLC-DPPH method was developed using an $85 \%$ ethanolic solution of the stable DPPH free radical to screen radical-scavenging compounds in miso extracts. A scheme of the instrumental setup is shown in Figure 1. HPLC-separated analytes reacted post-column with DPPH at a concentration of $100 \mu \mathrm{M} / \mathrm{L}$. The flow rate of the DPPH solution was set to $0.2 \mathrm{~mL} / \mathrm{min}$ (LC-10AD HPLC pump; Shimadzu, Japan), and induced bleaching was photometrically detected as a negative peak at $517 \mathrm{~nm}$. The length of the capillary used for the post-column reaction was adjusted to achieve a reaction time of $110 \mathrm{~s}$. The following equipment was used to separate the antioxidative components in extracts: LC-10AD HPLC pump; DGU-4A degasser; and a CTO-10AC column oven coupled with a pre-reaction photodiode array detector SPD-M10A, and post-reaction PDA SPD-M10AVP (all LC systems were purchased from Shimadzu Co., Japan). In addition, the following columns were used for the analysis: an ODS L-column $(150 \times 4.6 \mathrm{~mm}$ i.d.; Chemical Inspection \& Testing Institute, Tokyo, Japan) and a Nucleosil $\mathrm{C}_{18}$ column $(250 \times$ $4.0 \mathrm{~mm}$ i.d.; Macherey-Nagel Inc., USA) equipped with a guard column containing the same stationary phase. The mobile phase consisted of water containing $2 \%$ acetonitrile at a flow rate of $0.2 \mathrm{~mL} / \mathrm{min}$. The wavelengths used for detection were 220 and $280 \mathrm{~nm}$. Active fractions were collected, freeze-dried, and subsequently dissolved in water for further studies.

\subsection{Thin Layer Chromatography Analysis for Functional Properties}

The crude and active fractions $(5 \mu \mathrm{L})$ were spotted onto thin layer chromatography (TLC) plates (Silica gel 60 F254; Merk, Germany) for chromatographic separation using a mobile phase of $n$-butanol:aceticacid:water (4:1:1). Compounds containing amines were visualized using the ninhydrin reagent $(300 \mathrm{mg}$ dissolved in $100 \mathrm{~mL} n$-butanol and $3 \mathrm{~mL}$ acetic acid). For the detection of radical-scavenging compounds, DPPH $(500 \mu \mathrm{mol} / \mathrm{L})$ and galvinoxyl radical $(500 \mu \mathrm{mol} / \mathrm{L})$ solutions in methanol were used. A ferric (III) chloride (1\%) solution in methanol:water $(1: 1)$ was used for the detection of phenolic compounds. 


\subsection{Quantitative Analysis of the Amino Acids in Peptides}

The crude extract, active peptide fraction, or both were incubated with $6 \mathrm{MHCl}$ for $22 \mathrm{~h}$, neutralized by $\mathrm{NaOH}$ solution, and filtered. The amino acid concentrations were determined using an HPLC system (Shimadzu LC-10AT VP; Shim-pack-Amino-Li column, $6.0 \times 100 \mathrm{~mm}$ i.d.) with a fluorescence detector (Shimadzu RF-10A XL; Shimadzu Co., Japan). The temperature of the column (Shimadzu CTO-10A VP; Shimadzu Co., Japan) was set to $60^{\circ} \mathrm{C}$. Amino acid standard solutions (type AN II and B; Wako Pure Chemical Industries, Ltd., Japan) were used for identification and quantification.

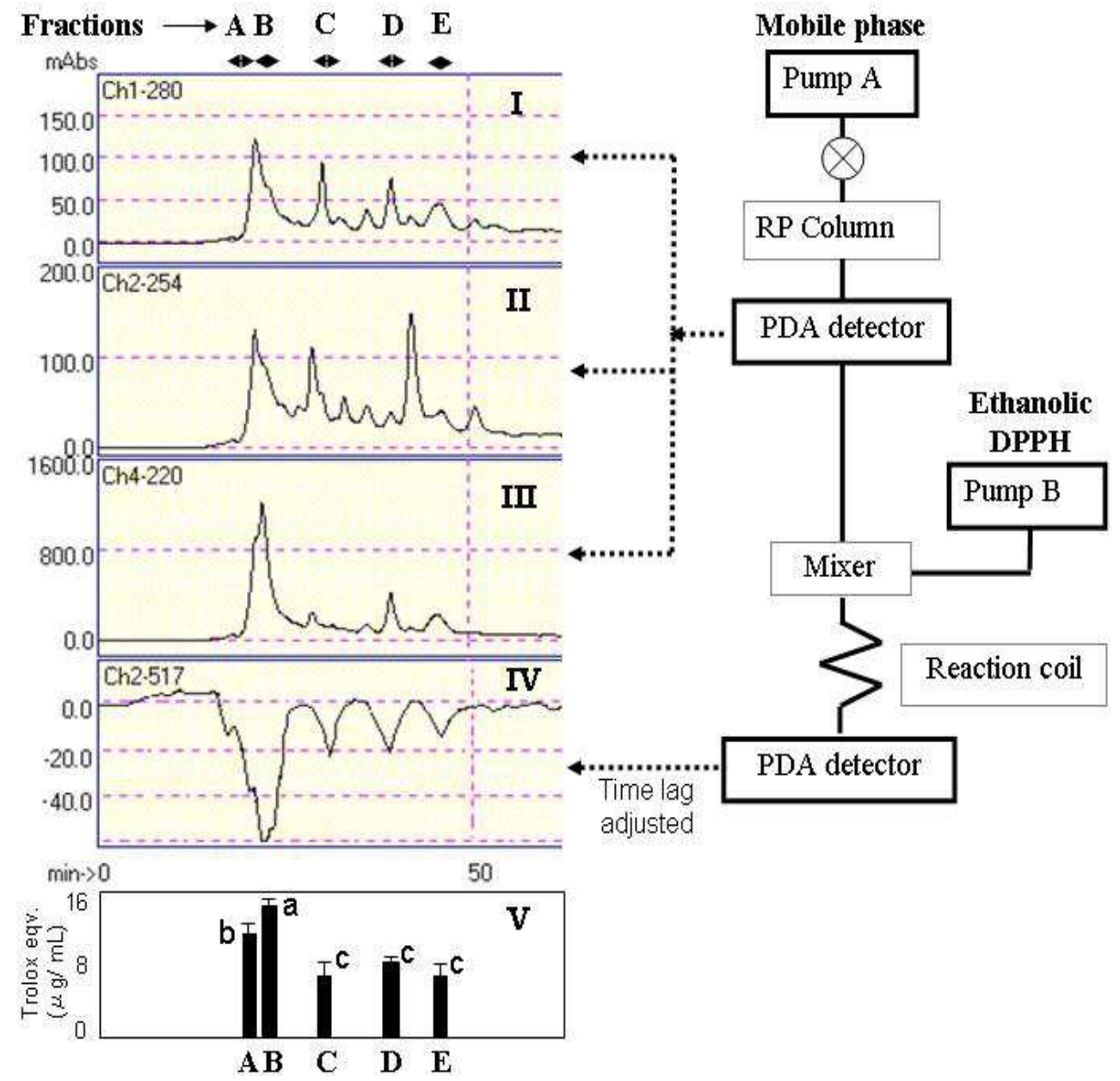

Figure 1.Screening of radical scavenging compounds through online HPLC DPPH system. I, II and III: chromatogram at 280, 254 and $220 \mathrm{~nm}$ respectively; $I V$ : chromatogram after reaction at $517 \mathrm{~nm}$; V: radical scavenging activity compared to trolox.

\subsection{Determination of Molecular Weight Distribution}

The fraction that exhibited the most potent antioxidant and free radical-scavenging activity was analyzed for molecular weight distribution. The fractions were loaded onto a TSK gel G2000 SWXL column $(7.8 \times 300 \mathrm{~mm}$ i.d., Tosoh, Tokyo, Japan), eluted with $45 \%$ (v/v) acetonitrile containing $0.1 \%(\mathrm{v} / \mathrm{v})$ trifluoroacetic acid at a flow rate of $0.5 \mathrm{~mL} / \mathrm{min}$, and monitored at $220 \mathrm{~nm}$. A molecular weight calibration curve was made using the following standards: cytochrome c $(12,500 \mathrm{Da})$ and aprotinin $(6500 \mathrm{Da})$ from Sigma; and bacitracin (1450 Da), tetrapeptide GGYR (451 .pDa), and tripeptide GGG (189 Da) from Peptides. The online DPPH radical-scavenging activity of the fractions was also measured.

\subsection{Statistical Analysis}

The Student's t-test was used to determine the statistical significance of differences between the mean values $(n=3)$. Correlation coefficients were calculated using the Microsoft Excel Data Analysis program. The level of significance was set to $P<0.05$.

\section{Results}

\subsection{DPPH Radical Scavenging Activity}

The relatively stable DPPH radical has been widely used to assess the antioxidant activity of compounds, which includes functioning as free radical scavengers or hydrogen donors [33]. Antioxidants donatehydrogen to free radicals, forming non-toxic species, which inhibit the propagation phase of lipid oxidation. The results shown in Figure 
2Aindicated that DPPH radical-scavenging activity increased with prolonged fermentation and storage at $25^{\circ} \mathrm{C}$. Fish miso extracts fermented for over 270 days exhibited almost $80 \%$ DPPH radical-scavenging activity.

\subsection{Hydroxyl Radical Scavenging Activity}

Because the radical system used for antioxidant evaluation can influence the experimental results, several radical systems were used to investigate the radical-scavenging activity of selected antioxidants [34]. Hydroxyl radicals are the most reactive free radicals that can be generated from superoxide anions and hydrogen peroxide in the presence of metal ions, such as copper or iron. The hydroxyl radical-scavenging activity of the fish miso extracts over fermentation and storage periods is shown in Figure 2B. The inhibition of hydroxyl radicals by fish miso extracts indicated that the substrate responsible for hydroxyl radical scavenging was rapidly developed during the early stages of fermentation. In the advanced stages of fermentation (over 135 days) for fish miso stored at $25^{\circ} \mathrm{C}$, the scavenging activity mostly remained stable. Although the radical-scavenging activity was comparatively lower, the activity of fish miso extracts stored at $10^{\circ} \mathrm{C}$ gradually increased until the end of the experiment.
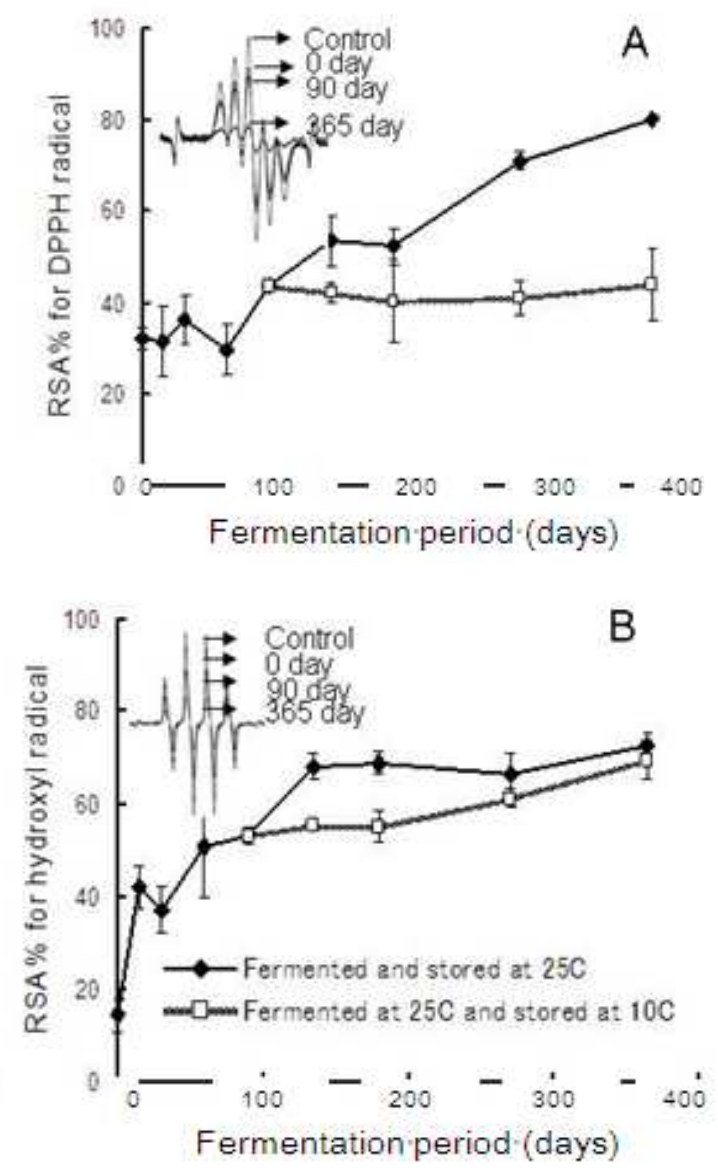

Figure 2. Changes of DPPH (A) and hydroxyl radical (B) scavenging activity ESR signal patterns of the fish miso extracted at different fermentation period and storage conditions.

\subsection{Nitric Oxide Radical Scavenging Activity}

NO is a potent pleiotropic mediator of physiological processes, such as smooth muscle relaxation, neuronal signaling, inhibition of platelet aggregation, and the regulation of cell-mediated toxicity [35]. The inhibition of NO by fish miso extracts revealed that under the experimental conditions used, radical-scavenging activity rapidly increased during a fermentation period of 90 days until all NO radicals were scavenged as shown in Figure 3C.

\subsection{Carbon-Centered Radical Scavenging Activity}

Carbon-centered radicals are one of the major radicals in our food system that can quickly react with $\mathrm{O}_{2}$ to yield peroxyl radicals that stimulate lipid peroxidation [36]. To investigate the efficacy of fish miso extract in inhibiting carbon-centered free radicals, we used the azo compound AAPH, which is often used as a hydrophilic radical initiator.
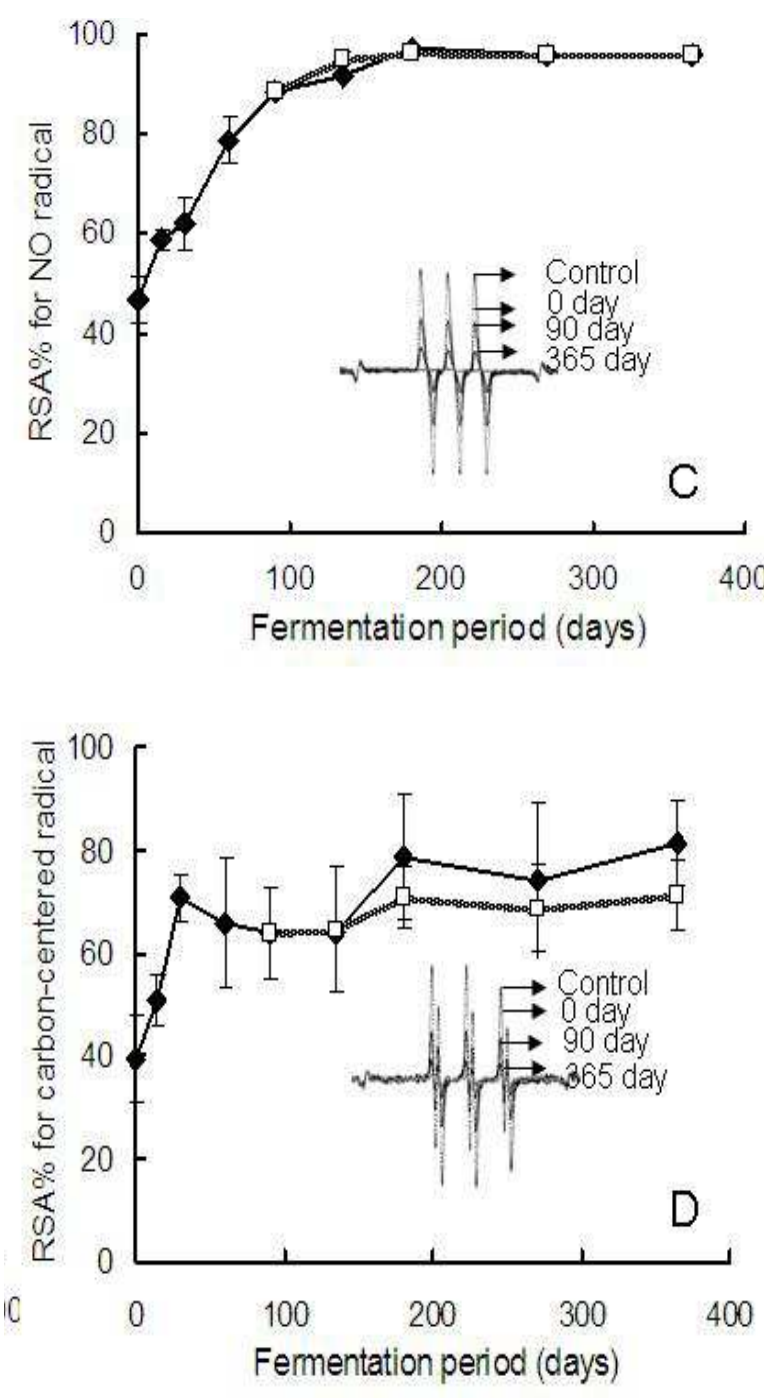

Figure 3. Changes of NO radical (C) and carbon-centered radical (D) scavenging activity and ESR signal patterns of the fish miso extracted at different fermentation period and storage conditions. 
The results of the carbon-centered radical assays shown in Figure 3D for different fish miso extracts clearly indicate that the substrate responsible for carbon-centered radical scavenging was rapidly produced during the early stages of fermentation. In the advanced stages of fermentation and storage, this radical-scavenging activity remained mostly stable; however, it gradually increased at higher storage temperatures of $25^{\circ} \mathrm{C}$.
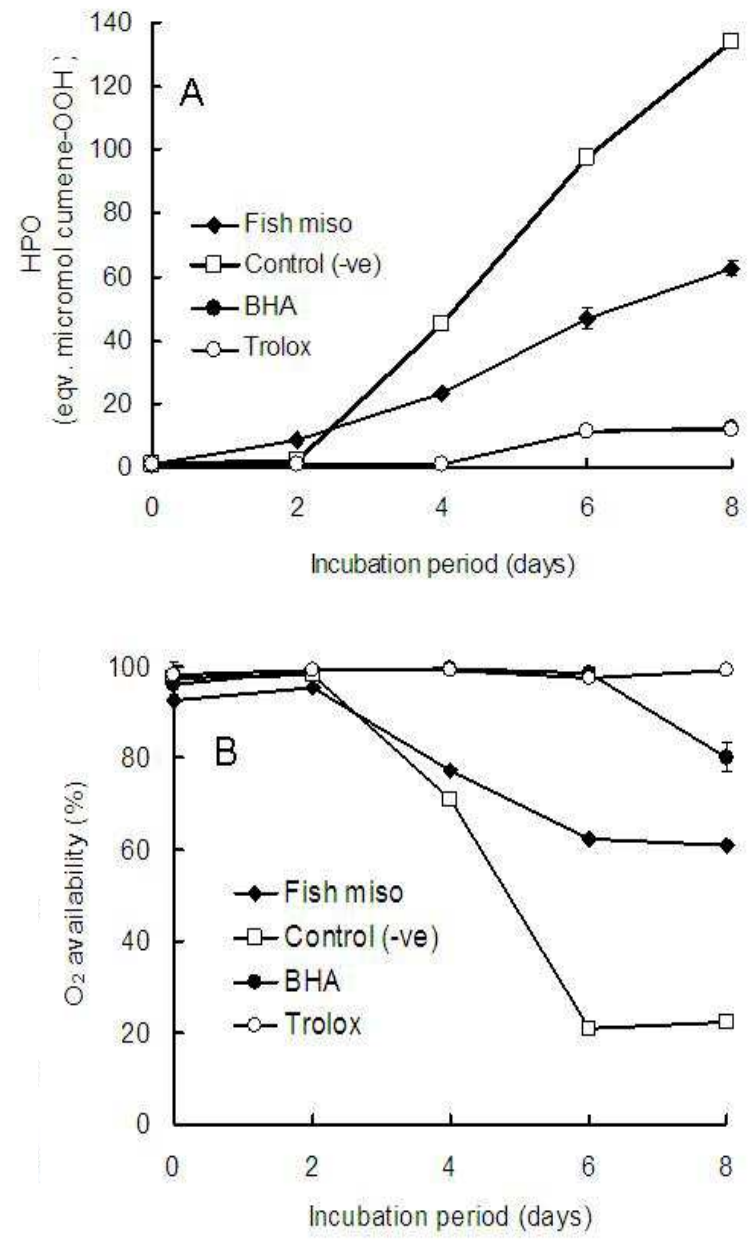

Figure 4. Changes of $\mathrm{HPO}(A)$ and $\mathrm{O}_{2}$ consumption $(B)$ in the linoleic acid model oxidation system during incubation period.

\subsection{Reducing Power Assay}

Different studies have shown that the antioxidant activity and reducing power of compounds are related [37,38]. The color of the reducing power assay changes to various shades of green and blue, depending on the reducingpower of different miso extracts. The substrates promote the reduction of the $\mathrm{Fe}^{3+}$ /ferricyanide complex to a ferrous complex. Therefore, measuring the formation of Perl's Prussian blue at $700 \mathrm{~nm}$ can determine the $\mathrm{Fe}^{2+}$ concentration. The reducing power of miso extracts at different fermentation and storage periods is shown in Figure 5. The reducing power increased rapidly during the very early stages of fermentation and remained stable for rest of the experiment. These results indicate that a substrate with reducing power was produced during the initial stages of fermentation.

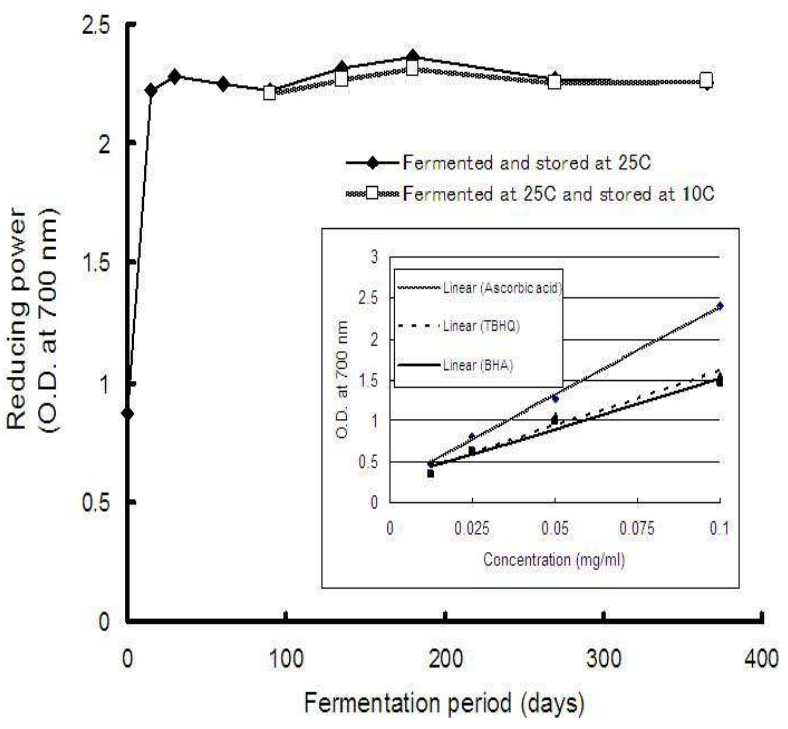

Figure 5. Changes of reducing power ability of the fish miso extracted at different fermentation period and storage conditions. Calibration curve of standard compounds are in inset.

\subsection{Protein Hydrolysis and Changes in Peptide Profile}

Figure 6 shows the SDS-PAGE of different peptides extracted from fish miso during different stages of fermentation and storage. Before fermentation, the major protein subunits of fish meat and rice koji can be clearly observed in the products at day 0 . During the early stages of fermentation, most of the high-molecular-weight peptides rapidly degraded due to protein hydrolysis. Over a fermentation period of 90 days, most of these peptides disappeared on the gel, indicating that the hydrolysis of high-molecular-weight peptides to low-molecular-weight oligopeptides and free amino acids was completed. Interestingly, some peptide subunits, particularly those of approximately $36.5 \mathrm{kDa}$ and $31.1 \mathrm{kDa}$, developed during the early stages of fermentation and became prominent over 30 days of fermentation. These protein subunits were probably resulted from the synthesis of protein by the starter $A$. oryzae (koji) mold, and this suggestion is strongly supported by the results of Ohtakiet al. [39] and Rashid et al. [40].

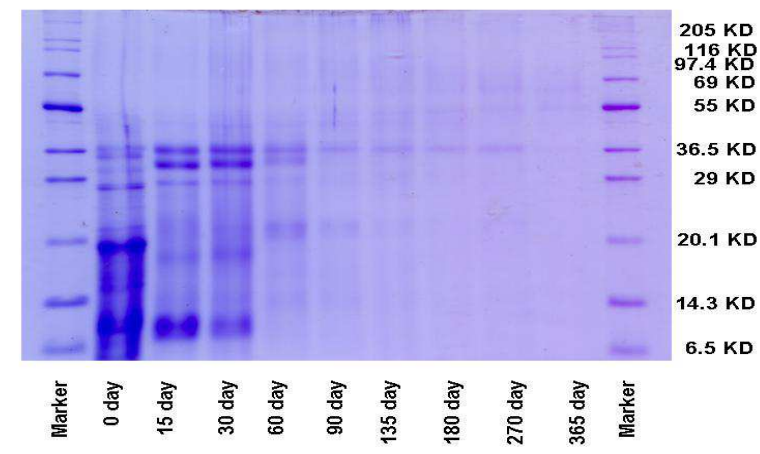

Figure 6. Changes in peptide patterns during the fermentation period of fish miso obtained from SDS-PAGE of water soluble fraction of fish. 


\subsection{Inhibition of Linoleic Acid Oxidation}

Fatty acid peroxidation can cause deleterious effects in foods by forming complex mixtures of secondary lipid peroxidation products. The intake of these foods can promote a number of adverse effects, including toxicityto mammalian cells. Therefore, the antioxidant activity of crude extract from matured fish miso was further characterized by assessing how it can inhibit the oxidation of linoleic acid. Lipid peroxidation is thought to proceed via a radical-mediated abstraction of hydrogen atoms from methylene carbons in polyunsaturated fatty acids [41]. The antioxidant properties of the crude extract from matured fish miso were investigated by measuring the formation of hydrogen peroxide and $\mathrm{O} 2$ consumption (results shown in Figures $7 \mathrm{~A}$ and $7 \mathrm{~B}$, respectively) and compared with the results obtained from assays containing BHA and Trolox ${ }^{\circledR}$. Theresults indicate that the oxidation of linoleic acid was markedly inhibited by the addition of crude fish miso extract. Many natural antioxidants are less potent than synthetic antioxidants. However, they can be used at higher concentrations than synthetic antioxidants because of their less restrictive toxicological parameters.
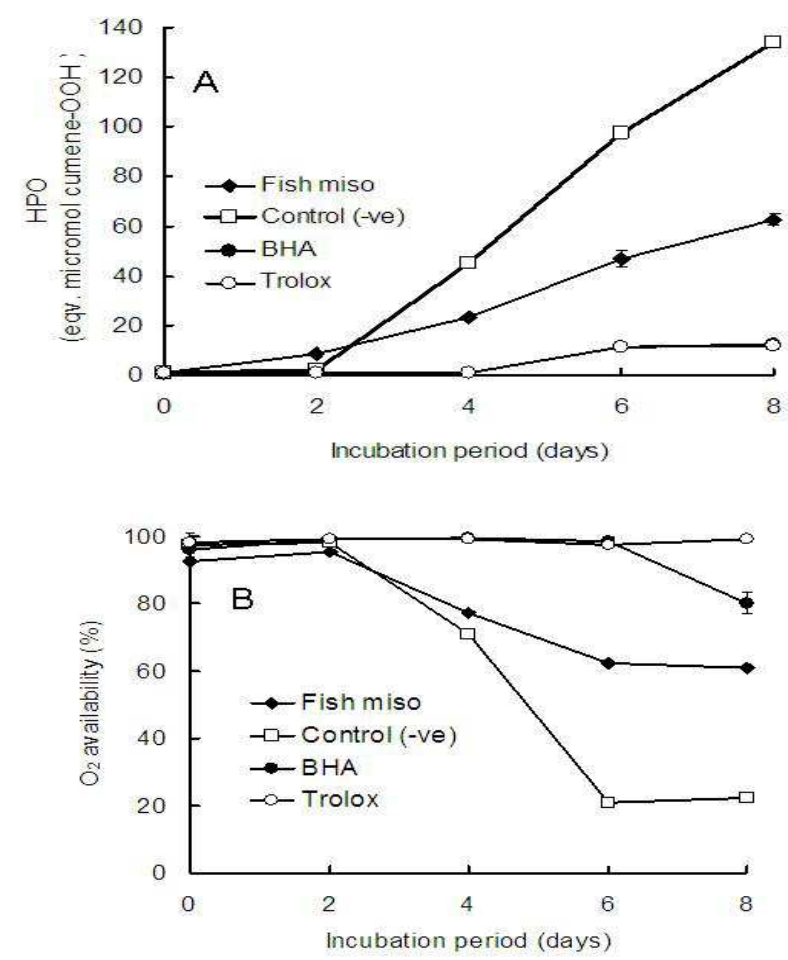

Figure 7. Changes of HPO (A) and O2 consumption (B) in the linoleic acid model oxidation system during incubation period.

\subsection{Screening of Radical-Scavenging Fractions and their Partial Characterization}

The online-HPLC-DPPH flow injection analysis shown in Figure 1 indicated the presence of 5 prominent radical-scavenging compounds in fish miso extract. However, quantitative DPPH scavenging activity indicated that fraction-B exhibited significantly higher scavenging capacity than those of other fractions. For further characterization of the potent fractions, TLC analysis with different stains was performed (Figure 8). TLC analyses indicated that crude extract as well as active fractions scavenged both DPPH and galvinoxyl radicals. All fractions were stained with ninhydrin. However, the crude extract and fraction-A were also stained by ferric chloride, indicating the presence of phenolic compounds. Developing the TLC plates spotted with crude extract and active fractions, and staining with a DPPH solution and ninhydrin reagent indicated that fraction-B (with low $\mathrm{Rf}$ amino-compound) was the most potent radical-scavenging compounds. The amino acid composition of peptides in matured fish miso extracts and active fractions shown in Table 1 demonstrated that the highly potent fraction-B was rich in some amino acids such as Glu (30.55 mol\%), Val (14.06 mol\%), Ala (10.50 mol\%), Lys (8.24 mol\%), Ser (6.06 mol\%), and His (4.91 mol\%). Notably, the molecular weight distribution of fraction-B indicated that low-molecular-weight peptides (below 500 Da) exhibited highest radical-scavenging activity.
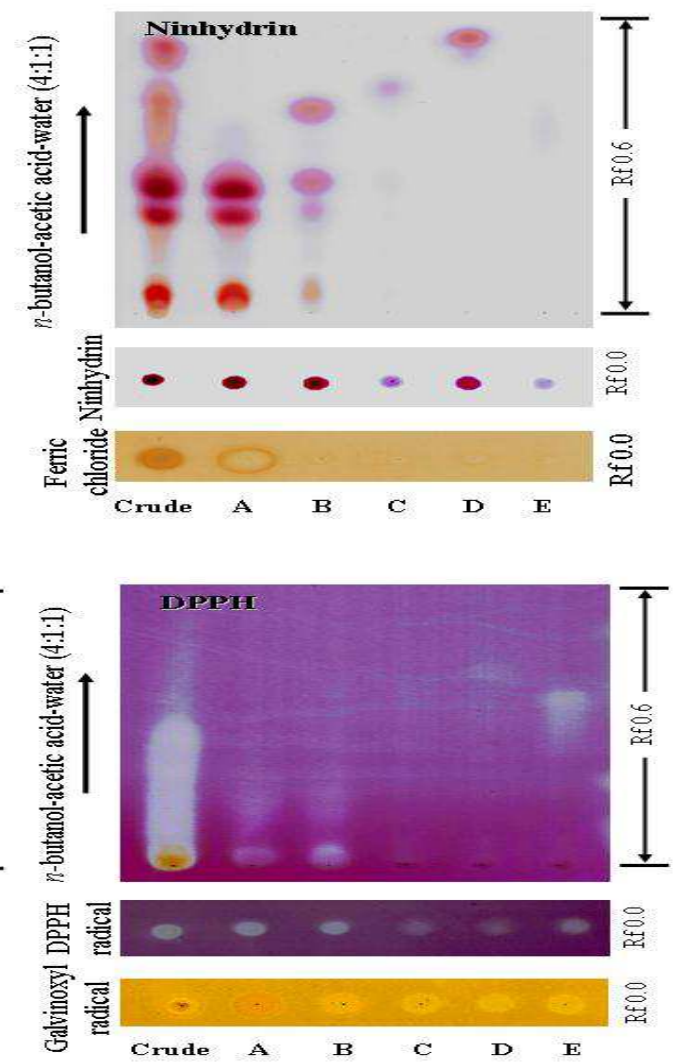

Figure 8.TLC analysis for active fractions. DPPH and galvinoxyl radical solution: applied for radical scavenging activity; ninhydrin: for amino compounds; Ferric chloride: for phenolics.

\section{Discussion}

Many fermented soybean foods, including miso, natto, tempeh, and fermented red bean exhibit improved antioxidant activity $[4,6,42]$. These soybean foods are made 
from whole soybeans containing substantial amounts of proteins, which are easily utilized by microorganisms. In the present study, fish miso, a paste of comparatively high protein content because of the application of koji inoculated with $A$. oryzae, was used as a substrate to obtain a functional food. Interestingly, fish miso exhibited reducing power and antioxidant activity, including scavenging of DPPH, hydroxyl, nitric oxide, and carbon-centered radicals, and inhibited linoleic acid oxidation after fermentation. The results of various radical-scavenging models to determine antioxidant activity demonstrated that the antioxidant compounds in fish miso could inhibit the formation of a variety of radicals. However, low-temperature storage may slow the developmental process of such active compounds. Furthermore, reducing power assays demonstrated that the antioxidants in fish miso can reduce the $\mathrm{Fe}^{3+} /$ ferricyanide complex to the ferrous form $\left(\mathrm{Fe}^{2+}\right)$. The reducing power of fish miso fermented with $A$. oryzaerapidly increased during the early stages of fermentation. This reducing power was also reflected in the anti-oxidation of lipids due to the reduction of peroxides. Fermentation with $A$. oryzaecould improve the reducing power of minced horse mackerel paste via koji fermentation. Some amino acids such as lysine, glycine, valine, and histidine, which are present in fish miso peptides, have been reported to exhibit antioxidant activities [43,44,45]. Notably, histidine exhibits a strong radical-scavenging activity due to the decomposition of its imidazole ring. As a result, fish miso may be a good source of antioxidants and serve as functional materials in food. The value of different trash fish could also be improved through $A$. oryzaefermentation.

In our study, we found that antioxidative peptides of low molecular weight play an important role in improving the antioxidant activity of fish miso. In addition, amino acids such as lysine, glycine, valine, and histidine, which have been reported to show antioxidant activity [46], may exhibit radical-scavenging activity in fish miso. Peptides derived from many protein sources with increased hydrophobicity have been reported to have antioxidative properties [47]. Thus, we speculate that hydrophobic amino acids (Leu, Val, and Ala) present in fish miso peptides exhibit the radical-scavenging properties of fish miso. Moreover, these amino acids have been reported to be effective in inhibiting the oxidation of fatty acids by using a linoleic acid model system [43]. The amino acid sequence of a peptide is also important for its antioxidative activity. Thus, the proper positioning of Glu, Leu, and His has been reported to improve radical-scavenging activities of antioxidative peptide sequences $[48,49]$. On the basis of these data, the radical-scavenging activity of this fish miso is speculated to be a result of the biophysical properties of some of the peptides produced during fermentation. The stoichiometry of reactions between the antioxidant compounds of fish miso extracts for a variety of radical-scavenging systems, including DPPH, hydroxyl, nitric oxide, and carbon-centered radicals, were different. These systems are usually used to explain for the difference in the scavenging potential of compounds. Therefore, other factors such as the stereoselectivity of radicals, solubility of extracts under different testing conditions, and/or different amino acids and peptide sequences may also affect the ability of fish misoto quench different radicals [50].

Some traditional soybean foods such as miso, natto, tempeh, and douchi $[4,6,51]$ are typically fermented using Bacillus, Aspergillus, Rhizopus, and Mucor spp., respectively. However, in the present study, the fish meat of horse mackerel was fermented using koji inoculated with $A$. oryzae. Aspergillus spp. can enhance the antioxidant activity and the flavor of fish miso without producing high levels of ammonia, which produces fishy flavor (data not shown). $A$. oryzaecould be a suitable microorganism to produce fish miso products with good flavor and functionality. In addition, the incorporation of protein hydrolysate in foods could confer desirable nutritional and functional properties [52]. We also did not exclude the antioxidant activity of other components such as phenolics, the Maillard reaction products, and amino acid sequences of the active peptides in fish miso. In the future, we plan to identify and characterize the bioactive peptide with high antioxidant activity found in fish miso fermented with $A$. oryzae.

\section{Conclusion}

The results obtained in this study demonstrate that enhanced antioxidant activity and nutritional quality can be obtained from fish miso produced via fermentation with $A$. oryzaeinoculated koji. The radical-scavenging activity and inhibition of linoleic acid oxidation may be due to the antioxidative peptides $(<500 \mathrm{Da})$ of the fish miso produced during the fermentation process. Therefore, the fish miso fermented using kojiinoculated $A$. oryzae, which possesses high antioxidant activity and a good flavor, could be used as a functional food. Fermentation with $A$. oryzaeoffers a novel strategy to enhance the value of a variety of trash fish, such as horse mackerel, to produce functional fish miso.

\section{References}

[1] J. P. Kehrer, "Free radicals as mediators of tissue injury and disease," Crit. Rev. Toxicol., vol. 23, 1993, pp. 21-48.

[2] N. Rajapakse, E. Mendis, W. K. Jung, J. Y. Je, and S. K. Kim, "Purification of a radical scavenging peptide from fermented mussel sauce and its antioxidant properties," Food Res. Int., vol. 38, 2005, pp. 175-182.

[3] N. GokturkBaydar, G. Ozkan, and S. Yasar, "Evaluation of the antiradical and antioxidant potential of grape extracts," Food Control, vol. 18, 2007, pp. 1131-1136.

[4] E. Berghofer, B. Grzeskowiad, N. Mundigler, W. B. Sentall, and J. Walcak, "Antioxidant properties of faba bean-, soybean-, soybean and oat tempeh," Int. J. Food Sci. Nutri., vol. 49,1998 , pp. $45-54$.

[5] B. F. Gibbs, A. Zougman, R. Masse, and C. Mulligan, "Production and characterization of bioactive peptides from 
soy hydrolysate and soy-fermented food," Food Res. Int., vol. 37, 2004, pp. 123-131.

[6] L. A. Santiago, M. Hiramatsu, and A. Mori, "Japanese soybean paste miso scavenges free radicals and inhibits lipid peroxidation," J. Nutri. Sci. Vitaminol., vol. 38, 1992, pp. 297-304.

[7] A. Kanda, Y. Hoshiyama, and T. Kawaguchi, "Association of lifestyle parameters with the prevention of hypertension in elderly Japanese men and women: a four-year follow-ip of normotensive subjects," Asia Pacific J. Public Health, vol. 11, 1999, pp. 77-81.

[8] M. Ohara, H. Lu, K. Shiraki, Y. Ishimura, T. Uesaka, O. Katoh, andH. Watanabe, "Prevention by long-term fermented miso of induction of colonic aberrant crypt foci by azoxymethane in F344 rats," Oncol. Rep., vol. 9, 2002, pp. 69-73.

[9] T. Kanazawa, T. Osanai, X.S. Zhang, T. Uemura, X.Z. Yin, K Onoder, Y. Oike, and K. Ohkubo, "Protective effects of soy protein on the peroxidizability of lipoproteins in cerebrovascular disease," J. Nutri., vol. 125, 1995, pp. 639S-646S.

[10] M. Horii, T. Ide, K. Kawashima, and T. Yamamoto, "Hypo-cholesterolemic activity of desalted miso in rats fed an atherogenic diet," Nippon ShokuhinKogakuKaishi, vol. 37,1990 , pp. 148-153

[11] D. D. Sastraatmadja, F. Tomita, and T. Kasai, "Production of high-quality oncom, a traditional Indonesian fermented food, by the inoculation with selected mold strains in the form of pure culture and solid inoculum," J. Graduate School of Agriculture, Hokkaido University, vol. 70, 2002, pp. 111-127.

[12] M. Matsuo, "Preparation and components of okara-ontjom, a traditional Indonesian fermented food," Nippon Shokuhin Kogyo Gakkaishi, vol. 44, 1997, pp. 632-639 (in Japanese).

[13] M. Matsuo and Y. Yumoto, "Preparation of tasty improved defatted soybean Ontjoms (fermented products with Neurosporaintermedia)," Food Sci. Technol. Res., vol. 5, 1999, pp. $168-170$

[14] M. Matsuo, "Antioxidant activity of fermented defatted soybean with Neurosporaintermedia, D-Ontjom," J. Jap. Soc. Nutri. Food Sci., vol. 54, 2001, pp. 305-309 (in Japanese).

[15] M. Matsuo, "Antioxidant activity of hydrophilic compounds of defatted soybean fermented with Neurosporaintermedia (D-Ontjom)," Food Sci. Technol. Res., vol. 8, 2002, pp. 253-238.

[16] M. Matsuo, "Plasma cholesterol reduction by defatted soy Ontjom (fermented with Neurosporaintermedia) in rats fed a cholesterol-free diet," J. Nutri. Sci. Vitaminol., vol. 46, 2000, pp. 30-33.

[17] M. Matsuo, "Plasma cholesterol reducing effect by okaraoncom (fermented with Neurosporaintermedia) in rats fed a cholesterol-free diet," ITE Lett. Batt., New Technol. Medicine, vol. 3, 2002, pp. 732-735.

[18] J. W. Bennett, "Taxonomy of fungi and biology of the Aspergillus," in Biology of Industrial Microorganisms, A. L. Demain and N. A. Solomon, Eds. London: The Benjamin/ Cummings Publishing Company, Inc., 1985, pp. 359-406.
[19] J. W. Bennett and M. A. Klich, "Aspergillus: Biology and industrial applications," in J. W. Bennett and M. A. Klich, Eds. 1992, pp. 134-137.

[20] K. B. Raper and D. I. Fennell, "The Genus Aspergillus," Baltimore: Williams and Wilkins, 1965, p. 686.

[21] Z. Kozakiewicz, "Aspergillus Species on Stored Products," Mycol. Pap., vol. 161, 1989, pp. 1-187.

[22] C. W. Hesseltine, "Future of fermented foods," Process Biochem., vol. 16, 1981, pp. 2-16.

[23] M. Raimbault and D. Alazard, "Culture method to study fungal growth in solid fermentation," Eur. J. Appl. Microbiol. Biotechnol., vol. 9, 1980, pp. 199-209.

[24] L. J. Yin, Y. L. Tong, and S. T. Jiang, "Improvement of the functionality of minced mackerel by hydrolysis and subsequent lactic acid bacterial fermentation," J. Food Sci., vol. 70, 2005, pp. 172-178.

[25] L. J. Yin, Y. L. Tong, and S. T. Jiang, "Effect of combining proteolysis and lactic acid bacterial fermentation on the characteristics of minced mackerel," J. Food Sci., vol. 70, 2005, pp. 186-192.

[26] F. Nanjo, K. Goto, R. Seto, M. Susuki, M. Sakai and Y. Hara, "Scavenging effects of Tea catechins and their derivatives on 1,1-diphenyl-2-picrylhydrazyl radical," Free Radic. Biol. Med., vol. 21, 1996, pp. 895-902.

[27] G. M. Rosen and E. J. Rauckman, "Spin trapping of superoxide and hydroxyl radicals," in Methods in enzymology, vol. 105, L. Packer, Ed. Orlando: Academic Press, 1984, pp. 189-209.

[28] K. Hiramoto, H. Johkoh, K. I. Sako and K. Kikugawa, "DNA breaking activity of the carbon-centered radical generated from 2,2-azobis(2 amidinopropane) hydrochloride (AAPH)," Free Radic. Res. Commun., vol. 19, 1993, pp. 323-332.

[29] M. Oyaizu, "Antioxidant activities of browning reaction prepared from glucosamine,” Jap. J. Nutri., vol. 44, 1986, pp. 307-315.

[30] T. Osawa and M. Namiki, "Natural antioxidnts isolated from eucalyptus leaf waxes,” J. Agric. Food Chem., vol. 33, 1985, pp. $777-780$.

[31] J. H. Sohn, Y. Taki, H. Ushio, and T. Ohshima, "Quantitative determination of total lipid hydroperoxides by a flow injection analysis system" Lipids, vol. 40, 2005, pp. 203-209.

[32] T. Ohshima, N. Li, and C. Koizumi, "Oxidative decomposition of cholesterol in fish products," J. Am. Oil Chem. Soc., vol. 70, 1993, pp. 595-600.

[33] C. L. Jao and W. C. Ko, "1,1-dipheny1-2-picrylhydrazyl (DPPH) radical scavenging by protein hydrolyzates from Tuna cooking juice,” Fish. Sci., vol. 68, 2002, pp. 430-435.

[34] L. Yu, S. Haley, J. Perret, M. Harris, J. Wilson, and M. Qian, "Free radical scavenging properties of wheat extracts," J. Agric. Food Chem., vol. 50, 2002, pp. 1619-1624.

[35] E. A. Hagerman, K. M. Riedl, G. A. Jones, K. N. Sovik, N. T. Ritchard, P. W. Hartzfeld, and T. L. Riechel, "High molecular weight plant polyphenolics (tannins) as biological antioxidants," J. Agric.Food Chem., vol. 46, 1998, pp. 
$1887-1892$

[36] B. Halliwell and J.M. Gutteridge, "Role of free radicals and catalytic metal ions in human disease: an overview," Methods Enzymol., vol. 186, 1990, pp. 1-85.

[37] P. D. Duh, "Antioxidant activity of burdock (ArctiumlappaLinne):Its scavenging effect on free radical and active oxygen," J. Am. Oil Chem. Soc., vol. 75, 1998, pp. 455-465.

[38] P. D. Duh, Y. Y. Tu, and G. C. Yen, "Antioxidant activity of waterextract of HarngJyur (Chrysanthemum morifolium Ramat)," LWT Food Sci. Tech., vol. 32, 1999, pp. 269-277.

[39] S. Ohtaki, H. Maeda, T. Takahashi, Y. Yamagata, F. Hasegawa, K. Gomi, T. Nakajima, and K. Abe, "Novel hydrophobic surface binding protein, HsbA, produced by Aspergillusoryzae," Appl. Environ. Microbiol., Apr. 2006, pp. 2407-2413.

[40] M. R. Rashid, M. R. Javed, T. Kawaguchi, J. Sumitani, and M. Arai, "Improvement of Aspergillusoryzae for hyperproduction of endoglucanase: expression cloning of cmc-1 gene of Aspergillusaculeatus," Biotechnol. Lett., vol. 30, 2008, pp. 2165-2172.

[41] N. Rajapakse, E. Mendis, H. G. Byun, and S. K. Kim, "Purification and in vitro antioxidative effects of giant squid musclepeptides on free radical-mediated oxidative systems," J. Nutri. Biochem., vol. 16, 2005, pp. 562-569.

[42] Y. C. Chung, C. T. Chang, W. W. Chao, C. F. Lin, and S. T. Chou, "Antioxidant activity and safety of the $50 \%$ ethanolic extract from red bean fermented by Bacillus subtilis IMR-NK1,” J. Agric. Food Chem., vol. 50, 2002, pp. $2454-2458$

[43] R. Marcuse, "The effect of some amino acids on oxidation of linoleic acid and its methyl esters," J. Am. Oil Chem. Soc., vol. 39,1962 , pp. $97-103$.
[44] M. Karel, S. R. Tannenbuam, D. H. Wallace, and H. Maloney, "Autoxidation of methyllinoleate in freeze-dried model systems. III.Effects of added amino acids," J. Food Sci., vol. 31, 1966, pp. 892-896.

[45] N. Yamaguchi, Y. Yokoo, and M. Fujimaki, "Antioxidative activities of protein hydrolyzates," Nippon Shokuhin Kogyo Gakkaishi, vol. 26, 1979, pp. 65-70.

[46] A. M. Wade and H. N. Tucker, "Antioxidant characteristics of L-histidine,” J. Nutri. Biochem., vol. 9, 1998, pp. 308-315.

[47] H. M. Chen, K. Muramoto, and F. Yamauchi, "Structural analysis of antioxidative peptides from soybean b-conglycinin," J. Agric. Food Chem., vol. 43, 1995, pp. 574-578.

[48] H. M. Chen, K. Muramoto, F. Yamauchi, and K. Nokihara, "Antioxidant activity of design peptides based on the antioxidative peptide isolated from digests of a soybean protein," J. Agric. Food Chem., vol. 44, 1996, pp. 2619-2623.

[49] K. Suetsuna, H. Ukeda, and H. Ochi, "Isolation and characterization of free radical scavenging activities peptides derived from casein," J. Nutri. Biochem., vol. 11, 2000, pp. $128-131$.

[50] J. F. Fan, M. Saito, Y. Y. Zhang, S. S. Tan, L. J. Wang, and E. Tatsumi, "Gel-forming ability and radical-scavenging activity of soy protein hydrolysate treated with transglutaminase," J. Food Sci., vol. 70, 2005, pp. 87-92.

[51] Y. C. Wang, R. C. Yu, and C. C. Chou, "Antioxidant activities of soymilk fermented with lactic acid bacteria and bifidobacteria," Food Microbiol., vol. 23, 2006, pp. 128-135.

[52] S. Y. Kim, J. Y. Je, and S. K. Kim, "Purification and characterization of antioxidant peptide from hoki (Johniusbelengerii) frame protein by gastrointestinal digestion," J. Nutri. Biochem., vol. 18, 2007, pp. 31-38. 